\title{
EFEITO DE MUDANÇAS SUCESSIVAS NA TRAJETÓRIA DE DEFORMAÇÃO NO COMPORTAMENTO MECÂNICO DO AÇO INOXIDÁVEL AISI 430*
}

\section{Resumo}

Rafael Alves Frederico de Alencar ${ }^{1}$ Maria Teresa Paulino Aguilar ${ }^{2}$ Elaine Carballo Siqueira Corrêa ${ }^{3}$ Giovanni Martins Júlio,4 Wellington Lopes ${ }^{5}$

O comportamento mecânico dos diferentes tipos de materiais é influenciado por diversas variáveis, dentre as quais, as condições adotadas para o processamento mecânico dos mesmos, as características estruturais e os aspectos metalúrgicos, por exemplo. Considerando essas variáveis, este trabalho apresenta o estudo do comportamento mecânico do aço inoxidável ferrítico AISI 430, estabilizado ao nióbio, para diferentes modos de pré-deformação: estampagem (estiramento) e tração com o subsequente carregamento em cisalhamento. Os resultados indicaram que o comportamento mecânico do material variou em função da direção de aplicação do esforço mecânico e do modo usado para a pré-deformação desse aço, ocasionando endurecimento e amaciamento.

Palavras-chave: Aço AISI 430; Cisalhamento e trajetória de deformação.

\section{EFFECT OF SUCESSIVE CHANGES OF STRAIN PATH ON THE MECHANICAL BEHAVIOR OF AISI 430 STAINLESS STEEL}

\begin{abstract}
The mechanical behavior of different types of materials is influenced by many variables, among which, the conditions used for the mechanical processing of the same, the structural characteristics and metallurgical aspects, for example. Considering these variables, this work presents the study of the mechanical behavior of the ferritic stainless steel AISI 430, stabilized niobium for two modes of predeformation: forming (stretch) and tensile with subsequent loading in shearing. The results indicated that the mechanical behavior of the material was affected by the direction that the mechanical behavior was applied and the mode used for the predeformation of this steel, occurring hardening and softening.
\end{abstract}

Keywords: AISI 430 steel; Shearing, Strain path.

1 Eng. Mecânico, Mestrando em Engenharia de Materiais, CEFET-MG, Belo Horizonte/MG, Brasil.

2 Professora, Departamento de Engenharia de Materiais e Construção, UFMG, Belo Horizonte/MG, Brasil.

3 Professora, Departamento de Engenharia de Materiais, CEFET-MG, Belo Horizonte/MG, Brasil.

4 Assistente Técnico Comercial, FAPE, Belo Horizonte/MG, Brasil.

5 Professor, Departamento de Engenharia de Materiais, CEFET-MG, Belo Horizonte/MG, Brasil. 


\section{INTRODUÇÃO}

Os aços inoxidáveis ferríticos tais como o AISI 430, são amplamente usados na indústria de linha branca e civil, devido à necessidade de operações de estampagem por embutimento e estiramento, por exemplo. No entanto, diversos defeitos de fabricação podem ocorrer durante a fabricação de diferentes tipos de objetos, os quais dependem, dentre outros aspectos, das características metalúrgicas e das condições de processamento aplicadas a tais materiais.

Neste contexto, a condição de estampabilidade dos diferentes tipos de materiais é afetada por diversas variáveis, dentre as quais se destaca a orientação cristalográfica assumida pelos mesmos devido à combinação das condições de processamento termomecânico [1].

Além da influência da orientação preferencial, vários outros fatores afetam a habilidade de um material resistir até o término de uma operação de estampagem, como a lei de encruamento desse material, a temperatura, a taxa de deformação e a maneira pela qual o mesmo é deformado (trajetória de deformação) [2 -4].

Considerando essa aboradgem esse trabalho apresenta a investigação do efeito do modo utilizado para a pré-deformação no comportamento mecânico do aço inoxidável ferrítico AISI 430, estabilizado ao nióbio, sendo essa análise feito a partir da combinação das rotas de processamento mecânico tração/cisalhamento e estiramento/cisalhamento.

\section{MATERIAL E MÉTODOS}

\subsection{Material}

Neste trabalho foi utilizado o aço inoxidável ferrítico estabilizado ao nióbio AISI 430 no estado recozido, com $1,2 \mathrm{~mm}$ de espessura inicial e composição química apresentada na Tabela 1.

Tabela 1. Composição química do aço AISI 430

\begin{tabular}{|c|c|c|c|c|c|c|c|c|}
\hline Elementos & $\mathrm{Cr}$ & $\mathrm{Mn}$ & $\mathrm{Co}$ & $\mathrm{V}$ & $\mathrm{Si}$ & $\mathrm{Ti}$ & $\mathrm{Ni}$ & $\mathrm{Nb}$ \\
\hline Valores (\%) & 16,0964 & 0,2458 & 0,0204 & 0,0445 & 0,2664 & 0,0021 & 0,2378 & 0,342 \\
\hline
\end{tabular}

\subsection{Modos de Pré-deformação}

\subsubsection{Tração}

A análise da influência do tipo de esforço mecânico utilizado para promover a prédeformação do aço AISI 430 foi feita a partir de duas rotas de carregamento: tração acompanhada por cisalhamento e estampagem (estiramento) acompanhada por cisalhamento. Para a pré-deformação em tração fez-se uso de uma máquina universal de ensaios Instron 5582 com sistema de aquisição de dados Blue Hill 2, com uso de extensômetro mecânico (tipo agulhas).

Para a condução da rota tração/cisalhamento os corpos de prova de tração confeccionados por eletroerosão a fio, de acordo com a norma ISO 50.

A pré-deformação em tração foi feita a partir da deformação em tração de $10 \%$ de deformaçaõ efetiva (deformação verdadeira) na direção da laminação original para posterior corte da amostras para condução do ensaio de cisalhamento. 


\subsubsection{Estampagem (Estiramento)}

O segundo modo utilizado para a pré-deformação do aço AISI 430 foi a estampagem, a partir de uma operação simplificada de estiramento com uso de uma prensa Spiertz, retirando-se em seguida, com uso de uma guilhotina Newton, amostras em duas posições diferentes (regiões 1 e 2 da Figura 1) para posterior ensaio de cisalhamento.

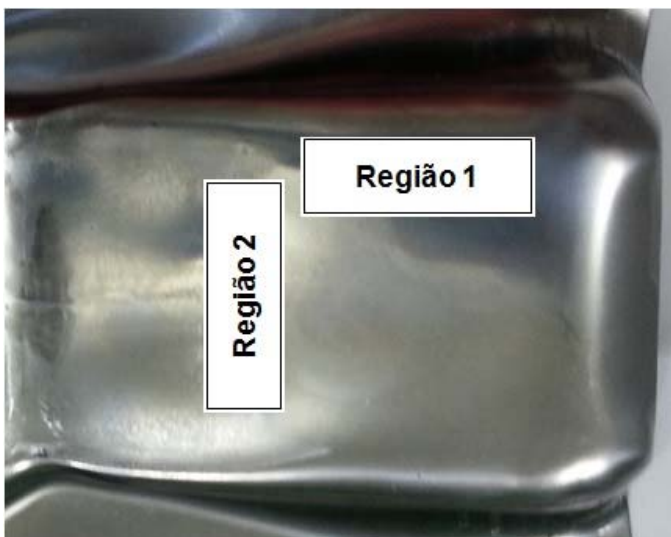

Figura 1. Aço AISI 430 estampado com indicação das regiões usadas para retirada dos corpos de prova de cisalhamento.

\subsubsection{Ensaio de cisalhamento}

Os ensaios de cisalhamento foram realizados com o uso de um dispositivo adaptado à máquina universal de ensaios Instron 5582 com uso de corpos de prova com comprimento (L) de $50 \mathrm{~mm}$ e largura de $15 \mathrm{~mm}$ (w), sendo a largura efetiva submetida ao ensaio de cisalhamento igual a $4,43 \mathrm{~mm}$.

Os ensaios foram realizados sob taxa de deformação de $0,005 / \mathrm{s}$ e conduzido em amostras no estado como recebido (amostras retiradas a $0^{\circ}, 45^{\circ}$ e $90^{\circ}$ da direção de laminação original das chapas), após as operações de pré-deformaçaõ em tração e por estampagem.

A conversão dos dados de tensão-deformação cisalhante em tensão-deformação efetiva foi feita com uso do coeficiente de Taylor [4].

\section{RESULTADOS e DISCUSSÕES}

\subsection{Comportamento Mecânico no Estado como Recebido (Recozido)}

A Tabela 2 apresenta o resumo das propriedades mecânicas obtidas para o aço AISI 430 no estado como recebido.

Na tabela 2 são mostrados valores de propriedade mecânica média das amostras do aço AISI 430 no estado como recebido, ensaiados em cada uma das três direções estudadas, $0^{\circ}, 45^{\circ}$ e $90^{\circ}$ em relação à direção de laminação em termos de: limite de escoamento em cisalhamento.

Tabela 2. Resumo das Propriedades Mecânicas do Aço AISI 430, $0^{\circ} \mathrm{DL}$

\begin{tabular}{|c|c|c|c|c|}
\hline \multicolumn{5}{|c|}{ Resumo Propriedades Mecânicas Aço AISI 430 (0 $\mathrm{DL})$} \\
\hline $\begin{array}{c}\text { Tensão limite } \\
\text { de } \\
\text { escoamento, } \\
\text { LE, (MPa) }\end{array}$ & $\begin{array}{c}\text { Tensão limite } \\
\text { de resistência } \\
\text { à tração, LRT, } \\
(\mathrm{MPa})\end{array}$ & $\begin{array}{c}\text { Tensão limite de } \\
\text { escoamento em } \\
\text { cisalhamento, K, } \\
(\mathrm{MPa})\end{array}$ & $\begin{array}{c}\text { Alongamento } \\
\text { uniforme, AU }(\%)\end{array}$ & $\begin{array}{c}\text { Expoente de } \\
\text { encruamento, } \mathrm{n}\end{array}$ \\
\hline $275 \pm 4,24$ & $425 \pm 30,02$ & $127 \pm 8,29$ & $22,95 \pm 2,04$ & 0,2373 \\
\hline
\end{tabular}


A Figura 2 apresenta curvas de tensão cisalhante em função da deformação cisalhante para o aço AISI 430 para cada uma das três direções estudadas, tais curvas indicam a anisotropia deste aço, sendo essa característica uma das principais variáveis na condição de estampabilidade dos diferentes tipos de aços quando submetidos, por exemplo, a operação de estampagem profunda [5].

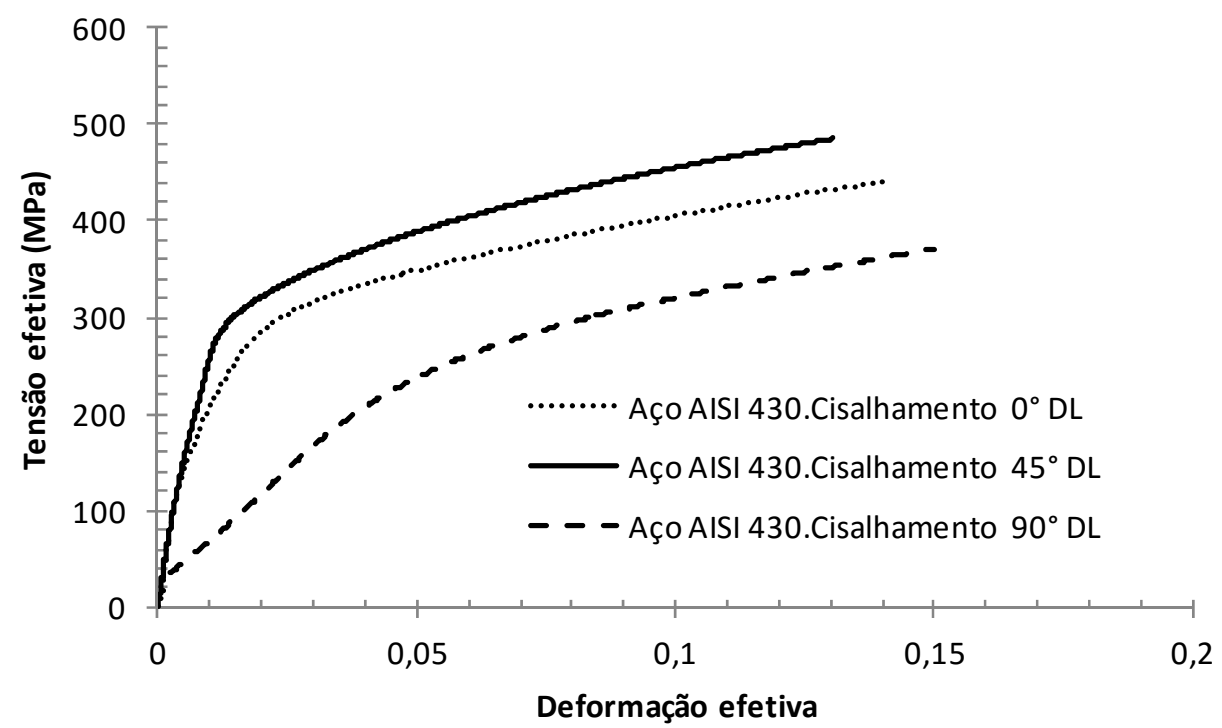

Figura 2. Curvas tensão - deformação cisalhante em função da direção de solicitação para o aço AISI 430.

\subsection{Comportamento Mecânico Após Mudança na Trajetória de Deformação}

\subsubsection{Rota Tração/Cisalhamento}

Na Figura 3 é apresentada é apresentada a curva de tensão-deformação efetiva para a rota de carregamento tração/cisalhamento. Pode-se perceber que após a prédeformação em tração de $10 \%$ de deformação efetiva que o material escoou em cisalhamento, para um valor de tensão de fluxo inferior ao detectado para o último estágio de deformação em tração $(\Delta \sigma$ igual a $410 \mathrm{MPa})$, caracterizando assim, a ocorrência do amaciamento do aço AISI 430 para essa rota de processamento mecânico.

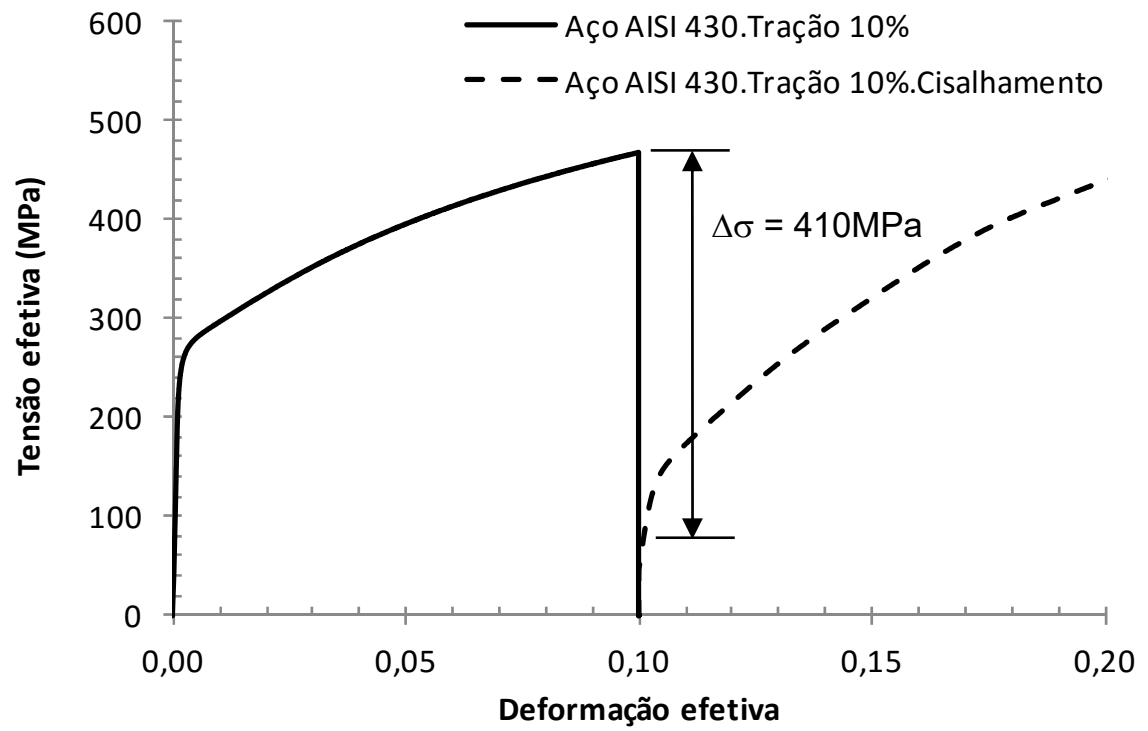

Figura 3. Curva de tensão-deformação efetiva para a rota tração/cisalhamento alicada ao aço AISI 430. 
Quando ocorre uma mudança abrupta no caminho de deformação a conformabilidade dos metais é severamente influenciada. Assim, a subestrutura de linhas de discordâncias criada durante a pré-deformação tende a se reorganizar para se adequar a outra típica do segundo modo de deformação plástica.

A parte macroscópica da evolução da subestrutura pode ser percebida pela diminuição ou aumento da taxa de encruamento, ocorrendo amaciamento, endurecimento e instabilidades plásticas, [6].

O amaciamento detectado após a pré-deformação em tração para a rota tração/cisalhamento pode ser relacionado com a presença de microdeformações plásticas localizadas, que conduzem ao desenvolvimento de microbandas de cisalhamento. Essas bandas são aproximadamente paralelas ao plano de deslizamento recém ativado, atravessando discordâncias "antigas", criando deste modo, canais novos para o deslizamento dos planos atômicos.

Esse fenômeno é mais comum de ser observado para valores reduzidos de deformação plástica, enquanto que com o acréscimo da deformação observa-se que as microbandas saturam e são transformadas em camada de deslocamento, a qual é associada com deslizamentos múltiplos [6].

A explicação para o comportamento de endurecimento por encruamento ou o amaciamento dos materiais após a estampagem quando comparado com o estado inicial dos mesmos deve considerar diversas variáveis, dentre as quais, as principais fontes de anisotropia, quais foram os sistemas de escorregamento ativos durante as condições de solicitação mecânica, a possível evolução subestrutural das linhas dediscordâncias e a evolução da textura ao longo de toda a condição de solicitação mecânica imposta aos dois aços inoxidáveis [7].

\subsubsection{Rota Estampagem/Cisalhamento}

De modo análogo, fez-se agora a estampagem do aço AISI 430 com posterior ensaio de cisalhamento, sendo as respectivas curvas de tensão-deformação efetiva das regiões 1 e 2 (vide Figura 1) apresentadas nas Figuras 4 e 5, respectivamente.

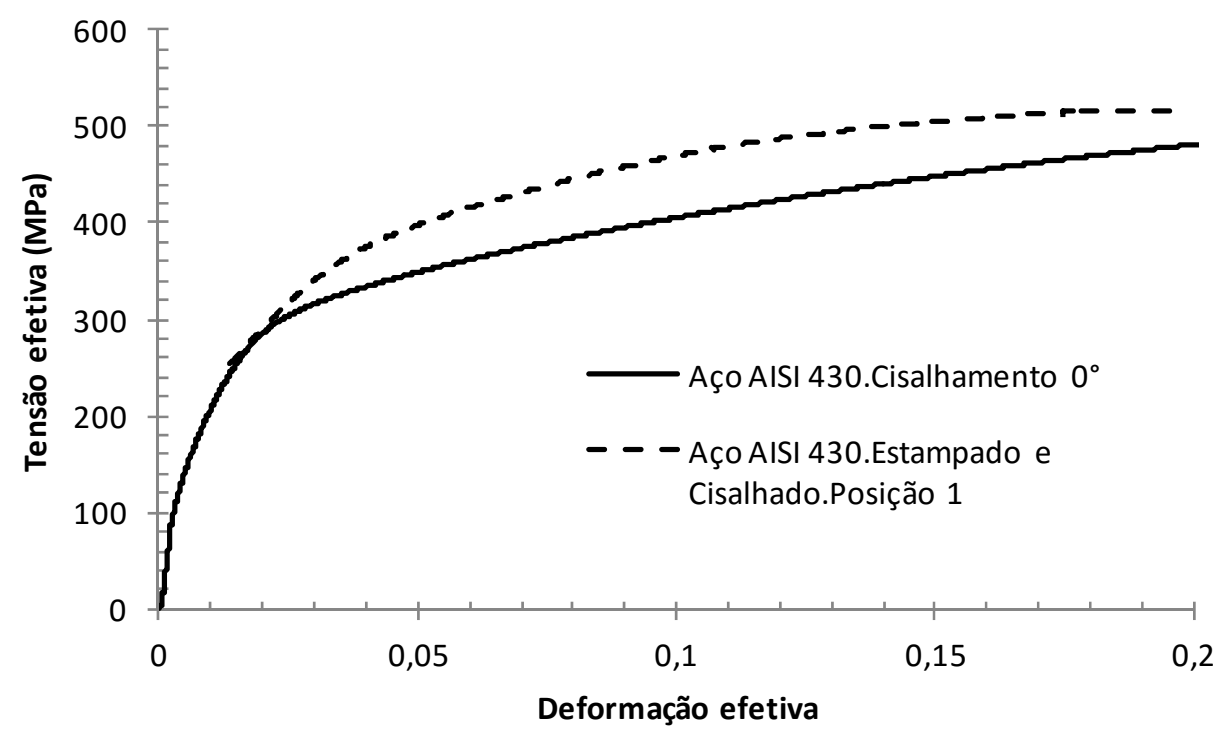

Figura 4. Curvas tensão-deformação efetiva do aço AISI 430 estampado e cisalhado, posição 1. 


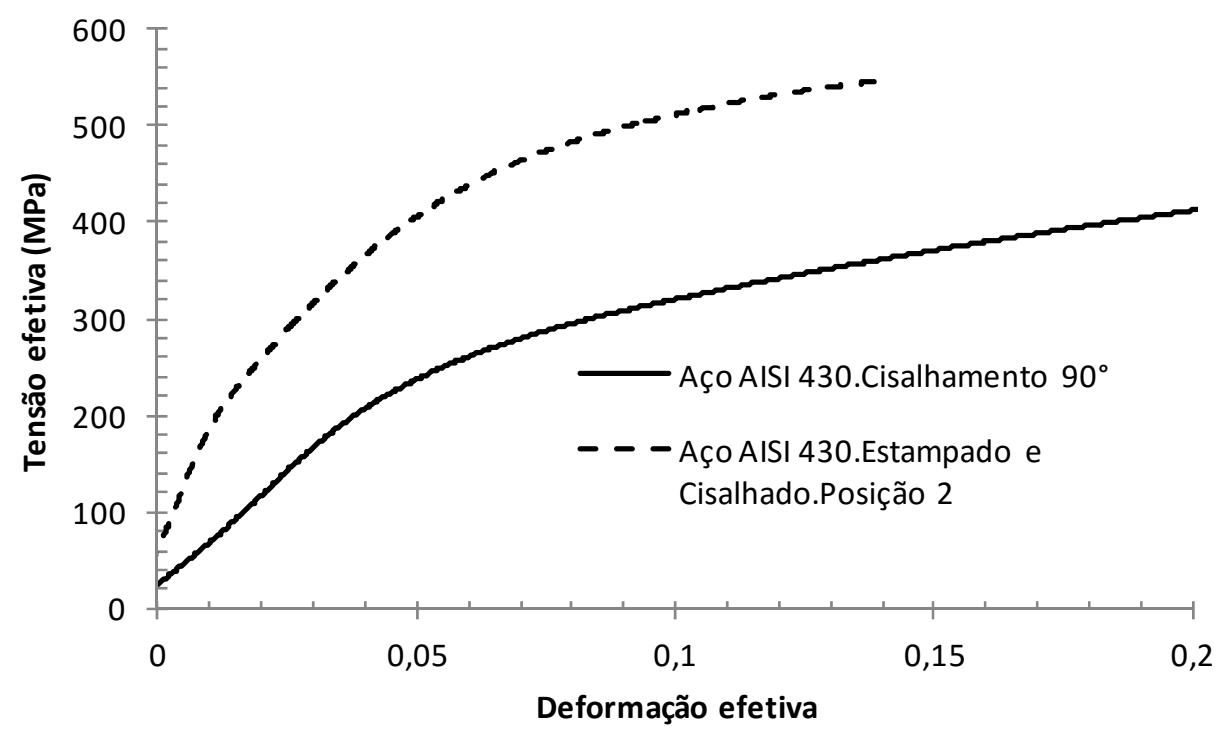

Figura 5. Curvas tensão-deformação efetiva do aço AISI 430 estampado e cisalhado, posição 2.

Nota-se que ocorreu endurecimento do aço AISI 430 após a operação de estampagem quando comparado com o estado inicial deste material, indicando assim, a ocorrência do endurecimento por encruamento desse material.

Outro resultado detectado após a observação das Figuras 4 e 5 é que a anisotropia do aço AISI 430 contribui para a magnitude do endurecimento. A amostra que foi retirada da posição 1 foi estampada na mesma direção de laminação original desse aço, enquando a amostra retirada da posição foi retirada a $90^{\circ}$ da direção de laminação, mas sendo ambas, pertencentes à mesma localização no produto estampado.

A Tabela 3 apresenta a evolução do valor do expoente de encruamento em função da rota de processamento mecânico.

Para as rotas de deformação plástica envolvendo a combinação de estampagem com cisalhamento, verificou-se que a amostra retirada da posição 2 apresentou o maior valor do expoente de encruamento quando comparada com a posição 1 da mesma região estampada, isso identifica o efeito da anisotropia do material na resistência mecânica do aço AISI 430, pois a diferença entre as mesmas foi apenas a direção de solicitação mecânica, $0^{\circ}$ e $90^{\circ}$ da direção de laminação, respectivamente.

Por fim, embora a rota de processamento composta pelos esforços de tração e de cisalhamento tenha exibido o amaciamento inicial durante o recarregamento em cisalhamento esta foi a condição de processamento que apresentou o maior valor para o expoente de encruamento. Esse resultado confirma a condição de o carregamento do tipo tração/cisalhamento, com o cisalhamento conduzido na mesma direção do ensaio de tração, ser uma condição de mudança severa da trajetória de deformação, como definido a partir do parâmetro alfa que determina a severidade da mudança na trajetória de deformação de um material [6].

Tabela 3 Valores do expoente de encruamento em função das rotas de processamento

\begin{tabular}{|l|c|}
\hline \multicolumn{2}{|c|}{ Resumo Propriedades Mecânicas } \\
\hline Rração/Cisalhamento & Expoente de encruamento \\
\hline Estampagem/Cisalhamento, posição 1 & 0,3535 \\
\hline Estampagem/Cisalhamento, posição 2 & 0,2289 \\
\hline
\end{tabular}




\section{CONCLUSÕES}

O estudo do comportamento mecânico do aço AISI 430 para as rotas de processamento tração/cisalhamento e estampagem/cisalhamento identificou:

a) a influência do modo de deformação plástica na ocorrência de amaciamento ou endurecimento para o subsequente carregamento em cisalhamento;

b) o efeito da direção de solicitação mecânica na intensidade do endurecimento para a rota estampagem/cisalhamento e

c) o amaciamento para a rota de deformação tração/cisalhamento.

\section{Agradecimentos}

Os autores agradecem à CAPES pelo auxílio por meio da concessão da bolsa de Mestrado.

\section{REFERÊNCIAS}

1. CARRAMANHOS, Douglas Martins, Texturas de deformação e recristalização de aços inoxidáveis ferríticos dos tipos AISI 430 e 409. 2006. Dissertação de mestrado - Ciência dos Materiais, Instituto Militar de Engenharia, Rio de Janeiro-RJ.

2. RAUCH, E. F. Plasticy of Metals During Cold Working Multiscale Phenomena in Plasticity. In J. Lépinoux et al. (eds) Multiscale Phenomena in Plasticity, Kluwer Academic Publishers, p. 303-318, 2000.

3. THUILLIER, S., MANACH, P. Y., MENEZES, L.F. Occurrence of strain path changes in a two-stage deep drawing process. Journal of Materials Processing Technology, v. 210, n. 2, p. 226-232, 2010.

4. RAUCH, E. F. The flow law of mild steel under monotonic or complex strain path. Solid state phenomena, v.23, p. 317 - 334, Janeiro, 1992.

5. LOPES, Wellington. Efeito da pré-deformação e direção de solicitação no comportamento mecânico do aço inoxidável AISI 430 com o uso do ensaio de cisalhamento para alterar a trajetória de deformação. 2006. Dissertaçao de mestrado Engenharia Mecânica. Universidade Federal de Minas Gerais. Belo Horizonte.

6. LOPES, Augusto Luís Barros. Análise microestrutural das instabilidades plásticas em materiais metálicos, 2001. Tese de Doutorado - Engenharia Cerâmica e do Vidro. Universidade de Aveiro, Portugal.

7. PEETERS, B., et al. Work-hardening/softening behaviour of bcc polycrystals during changing strain paths: I. An integrated model based on substructure and texture evolution, and its prediction of the stress-strain behaviour of an IF steel during two-stage strain paths. Acta Materialia, v. 49, n. 9, p. 1607-1619, 2001. 